\title{
Soot morphological differences between laminar diffusion flames of traditional aviation kerosene and Bio-kerosene
}

\author{
Yiyang Yang \\ School of Energy and Power Engineering, \\ Beihang University \\ yyy1530@buaa.edu.cn \\ Beijing, China
}

\author{
Zhiwen Gan \\ School of Energy and Power Engineering, \\ Beihang University \\ 09651@buaa.edu.cn \\ Beijing, China
}

\begin{abstract}
In recent years, the application of biomass alternative kerosene in aero engines has aroused great public interest due to environmental concerns. On the other hand, the laminar diffusion flame is suitable to study the evolution of soot since it is convenient to collect soot particles at different development stages. In this study, the evolution of soot morphology and nanostructure in a free jet laminar diffusion flame of algae-based biofuel was compared with that of Chinese traditional RP-3 aviation kerosene. The burner was designed and manufactured in the laboratory. The differences of height, temperature, profile and other characteristics between the two flames are also concerned. A new direct sampling method was developed to collect soot samples in the flames. Compared to the traditional thermophoresis probe sampling method, it has the advantages of longer sampling time and lower-disturbing to the flame. Transmission electron microscopy (TEM), high-resolution transmission electron microscopy (HRTEM), X-ray diffraction (XRD)and elemental analyzer were applied to this investigation. Compared with the biomass soot, the RP-3 soot at the tip of the flame has longer fringe length and smaller layer spacing, which indicates a higher degree of graphitization. The information of this study will be benefit to the further application of biomass aviation alternative fuels in the aero engines.
\end{abstract}

\section{INTRODUCTION}

In face of increasingly serious global environmental problems, the search for sustainable renewable alternative energy has become an urgent topic for human beings. Since aviation pollutants are mainly concentrated in the stratosphere, their greenhouse effect is higher than other surface emissions. As one of the main pollutants of aero- engines, soot is a highly carbonized, solid-phase compound with a particle size scale of nanometer, in which the carbon mole fraction is over 0.85 (Wang, X. et al.,2018) . Due to its small particle size, high diffusivity and strong sorption capacity of heavy metals and toxic larger polycyclic aromatic hydrocarbons (PAHs), soot has become a severe threat to atmospheric environment and human health, thus a major concern in aero-engine pollutant emission control. However, according to the existing literature, the current understanding of the mechanism of soot formation is far from complete. In addition, soot reduces combustion efficiency, and soot deposition may also cause damage to the turbine blades of aero engines. The study of soot particles properties not only increases the knowledge of combustion mechanism, but also provides the theory foundation for the research on hydrocarbon fuel-efficient combustion and low pollution emission of aircraft engines.

Nanostructure characteristics of soot primary particles, such as the size of crystallite size, tortuosity of graphite layers and their inter-layer distance have recently gained the attention of researchers due to their correlation with oxidative reactivity. Furthermore, such information will provide fundamental understandings of the soot formation process (Ghiassi, H.et al., 2016). Laminar free jet diffusion flame is very suitable for studying the soot evolution process $(\mathrm{Li}, \mathrm{Z}$. et al., 2018). First of all, it represents a simpler version of complex practical flames (Santoro, RJ.et al., 1987). Secondly, it has all of the physical and chemical processes that affect soot formation (Liu, F.et al., 2003). At last, the laminar free jet flames are multi-dimensional and relatively simple to numerical model calculation (Smoke, MD. et al., 1999). Some researchers studied the morphology evolution of soot by sampling at the centerline and an outer streamline of laminar free jet diffusion flame of a surrogate for Jet A-1( Kholghy, M. et al.,2013). They observed the transition process that the 
solid soot particle inception to liquid PAH and then to solid soot particles (carbonization). Some researchers used HRTEM and EELS to study the evolution of carbon smoke nanostructures from methane flame. They concluded that the nascent methane soot presents the predominance of large coalesced disordered structures in comparison to young, intermediate and mature soot presenting spherule aggregates. (Apicella, B.et al., 2018)

In this study, the laboratory-prepared algae-based biomass alternative kerosene and Chinese traditional RP-3 aviation kerosene were applied as the fuels of the laminar free jet flames by a laboratory burner. The evolution of soot morphology in the laminar free jet diffusion flame of algaebased biofuel was compared with that of Chinese traditional RP-3 aviation kerosene. A new direct sampling method is used to sample at different heights along the central axis of the flames. Transmission Electron Microscopy (TEM), high resolution transmission electron microscopy (HRTEM), X-ray diffraction (XRD) and elemental analyzer were applied to analyze of soot characteristics, mainly on the evolution of soot morphology and structure.

\section{METHODOLOGY}

\subsection{Fuels}

The algae-based oil used in this study is prepared by direct hydrogenation of nannochloropsis oil, and its main components include octane, nonane, tridecane, tetradecane, pentadecane, hexadecane, heptadecane and octadecane (Zhao, B., 2017). The RP-3 aviation kerosene is currently a relatively common fuel for civil aviation aircraft in China, and its main components are shown in Fig. 1.

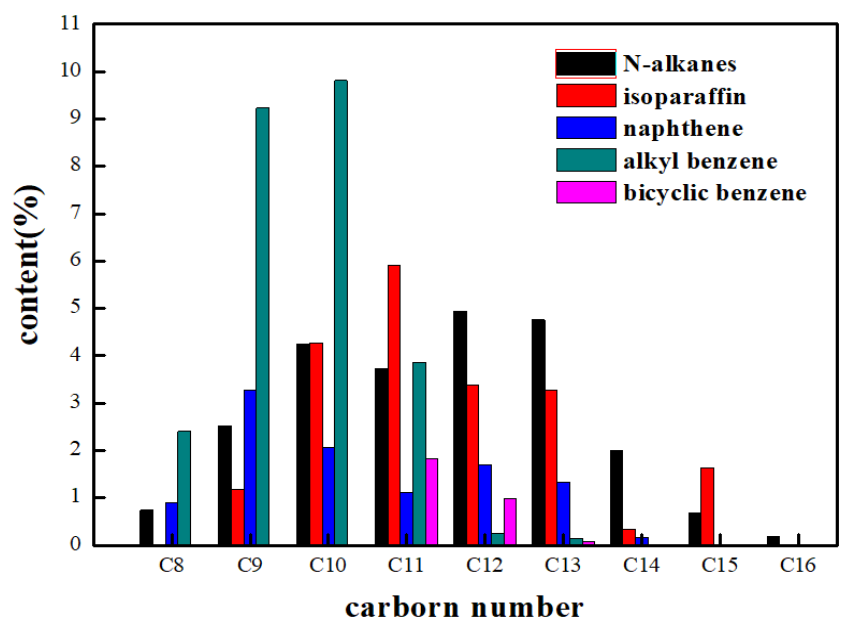

Fig. 1. Composition of Chinese RP-3 kerosene used in this investigation

\subsection{Experimental setup}

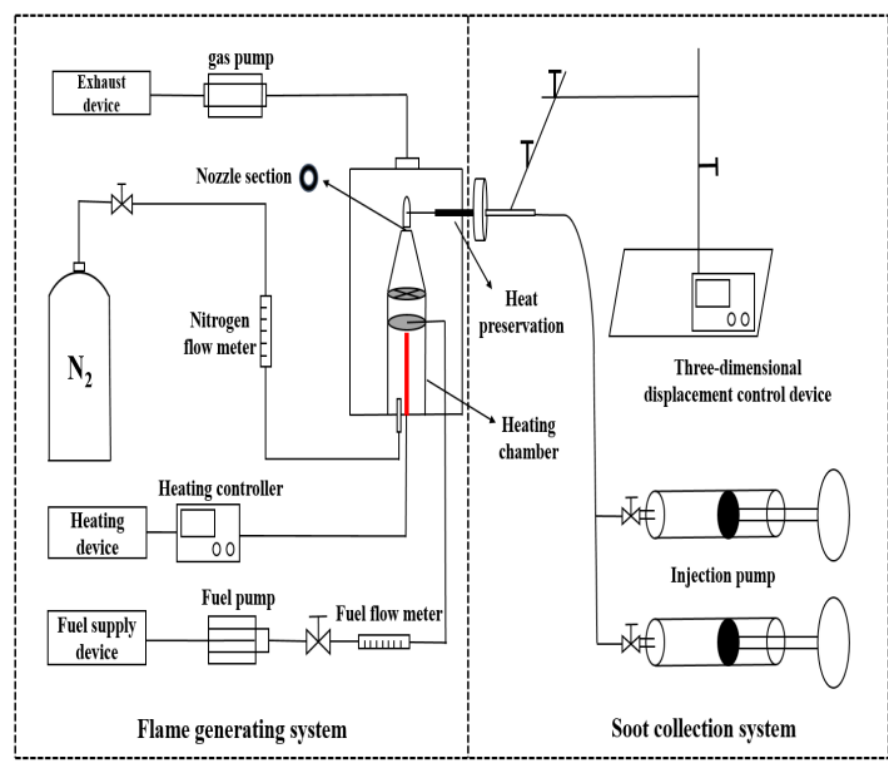

Fig. 2. Schematic diagram of the experimental device

The experimental setup of this study is shown in Fig. 2, which is mainly composed of a flame generating device and a soot sampling device. The liquid hydrocarbon fuel needs to be pre-evaporated during the experiment since both of the fuels are liquid at room temperature. The fuel is blended with nitrogen and then preheated to $673 \mathrm{~K}$ in the heating chamber using a heater equipped with a temperature controller to ensure that the fuel evaporates completely. Nitrogen is applied as the carrier gas to form the high temperature fuel steam that is ejected through the nozzle. The nozzle section is a ring with an inner diameter of $6 \mathrm{~mm}$ and an outer diameter of $10 \mathrm{~mm}$. In this investigation, the nitrogen volume flow rate was $100 \mathrm{ml} / \mathrm{min}$, and the corresponding mass flow rate was $0.136 \mathrm{~g} / \mathrm{min}$. The fuel is driven by a syringe pump, and the nitrogen is supplied by a high pressure cylinder. This experiment was carried out in the atmospheric environment, and the volume flow rate of two fuels was $0.166 \mathrm{ml} / \mathrm{min}$ at room temperature.

\subsection{Soot sampling}

\subsubsection{Direct sampling}

In this study, a new direct sampling method which is based on the general thermophoretic sampling method was used to collect particle samples in the flame. The system sketch is shown in Fig. 1. The direct sampling method uses a corundum tube having an inner diameter of $1 \mathrm{~mm}$ and an outer diameter of $2 \mathrm{~mm}$ as the sampling probe. Corundum tubes have almost no catalytic effect on flame intermediates, ensuring the authenticity of sampling. The syringe creates a negative pressure to draw in the combustion intermediate. TEM grid and polytetrafluoro ethylene ( PTFE) membranes were used to filter the particles and sample them. The probe's disturbance to the flame during the experiment is relatively weak, to ensure the accuracy of the sampling (as shown in Fig. 3). Compared to the general thermophoretic 
sampling method, the direct sampling method can realize the precise control of the sampling point and time with minimized disturb. It is suitable for complex flame also. Since the sampling time of the thermophoresis sampling method is limited due to the fast heating rate of TEM grid, it cannot be used in the case where the soot concentration is thin. The direct sampling does not have this problem. In addition, the liquid phase and gas phase samples in the flame can be collected simultaneously by this method if necessary.
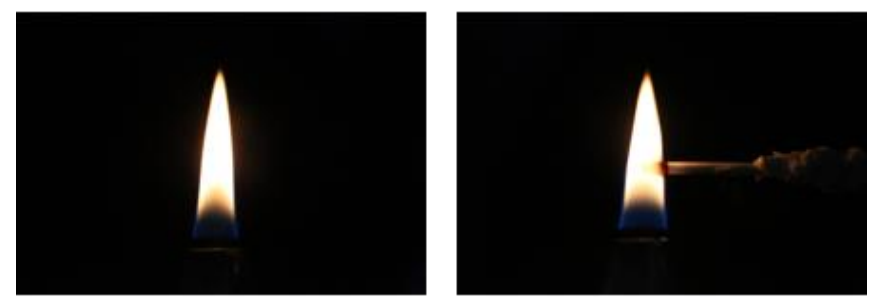

Fig. 3. Direct sampling (The left picture shows the normal combustion flame, and the right picture shows the sampling process.)

The composite sampling membrane used in this study has a combined structure which consists of a PTFE membrane and two TEM grids for transmission electron microscopy as shown in Fig 4. The PTFE membrane is an organic membrane with the advantages of large gas permeability, low resistance and high particle rejection. It is suitable to collect particle and analyze the sample by conventional deposition methods. TEM grid is a special carrier used for transmission electron microscopy to detect samples. It is mainly used for the characterization of nanomaterials, biomaterials, soot and other microscopic substances. It is one of the most commonly used support membranes in general thermophoretic sampling method. Since the general sample preparation process of TEM requires ultrasonic vibration, which is likely to damage the internal structure of the soot particles and affect the observation of the accumulation of soot morphology. Therefore, the samples collected on the TEM grid were directly subjected to TEM analysis during the experiment to avoid the influence of the ultrasonic oscillation process on the observation of soot morphology. There is a circular hole with a diameter of $2.5 \mathrm{~mm}$ in the center of the two PTFE membranes. The TEM grid with a diameter of $3 \mathrm{~mm}$ was inserted between the two PTFE membranes and adjusted to be located at the center.
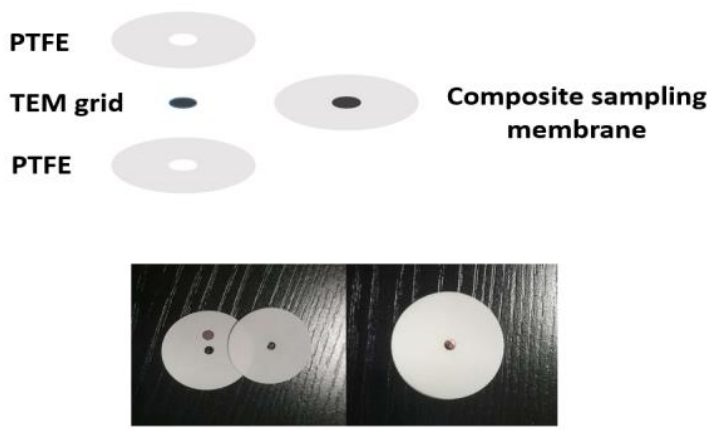

Fig. 4. Composite sampling membrane

The PTFE membrane serves as a carrier for the carbon support membrane in the sampling device to ensure the structural stability of TEM grid. During the experiment, the sampling probe is fixed on a three-dimensional displacement device for precise positioning. The precision of the displacement in $\mathrm{x}, \mathrm{y}$, and $\mathrm{z}$ directions are set to $0.1 \mathrm{~mm}$ in this investigation.

\subsubsection{Sampling positions}

The flame height of RP-3 aviation kerosene was measured by the three-dimensional displacement device to be about $27 \mathrm{~mm}$, and the flame height of biomass was about $18 \mathrm{~mm}$ under the same working condition. In view of the different flame heights generated by the two fuels, the heights of sampling positions were normalized by dimensionless height since it is convenient for discussion. The specific parameters are shown in table 1 . The four sampling points are set at the dimensionless heights (The following is replaced by H) of $0.25,0.5,0.75$, and 1 . Samples obtained by direct sampling were used for TEM and HRTEM analysis, while elemental analysis was applied to the soot samples by conventional thermophoresis-based deposition methods.

Table 1 Sampling point setting

\begin{tabular}{ccccc}
\hline & $\begin{array}{c}\text { Sampling } \\
\text { Point 1 }\end{array}$ & $\begin{array}{c}\text { Sampling } \\
\text { Point 2 }\end{array}$ & $\begin{array}{c}\text { Sampling } \\
\text { Point 3 }\end{array}$ & $\begin{array}{c}\text { Sampling } \\
\text { Point 4 }\end{array}$ \\
\hline $\begin{array}{c}\text { RP-3 height } \\
(\mathrm{mm})\end{array}$ & 7.5 & 15 & 22.5 & 30 \\
$\begin{array}{c}\text { Biomass } \\
\text { height }(\mathrm{mm})\end{array}$ & 4.5 & 9 & 13.5 & 18 \\
$\begin{array}{c}\text { Dimensionless } \\
\text { height }\end{array}$ & 0.25 & 0.5 & 0.75 & 1 \\
\hline
\end{tabular}

\subsection{TEM and HRTEM}

Transmission electron microscope and high-resolution transmission electron microscope (200KV, JEM2100F, JEOL, Japan) were applied to the observation of soot nanostructure. TEM is used to observe the morphology of soot, and to understand the changes in the morphology of soot in the primary, growth and maturity stages of soot. HRTEM is used for the characteristics of soot fringe property which includes three aspects: fringe length, microcrystalline layer spacing, fringe tortuosity. Structurally, amorphous soot particles are typically characterized by a shorter fringe length and a disordered carbon layer, while graphitic carbon has a longer fringe length and a smaller interfringe spacing. As the degree of graphitization increases, the layer spacing approaches the distance between the equilibrium planes by $0.335 \mathrm{~nm}$ (Chen, X.et al., 2013). Hence, the fringe length and spacing can yield useful information about the degree of crystallinity of a carbon nanostructure. The fringe length is also used to indicate the size of polycyclic aromatic hydrocarbon $(\mathrm{PAH})$ molecules in soot particles (Apicella, B.et al., 2015 and Mathews, JP. et al., 2010). Due to the presence of the C5 ring, the fringe tortuosity (a measure of the curvature of the fringe) is related to the curvature of the PAH (Botero, ML.et al., 2016). In addition, it is believed that the fringe tortuosity is also related to the oxidizing properties of soot particles (Matti, M.et al., 2003). 


\subsection{Flame shape and temperature}

Fig. 5 shows the laminar diffusion flame formed by the combustion in the nitrogen transport environment used in this study. The left side is the RP-3 aviation kerosene flame and the right side is the biomass flame. Both are candle-shaped flames, and the flame of biomass is brighter.
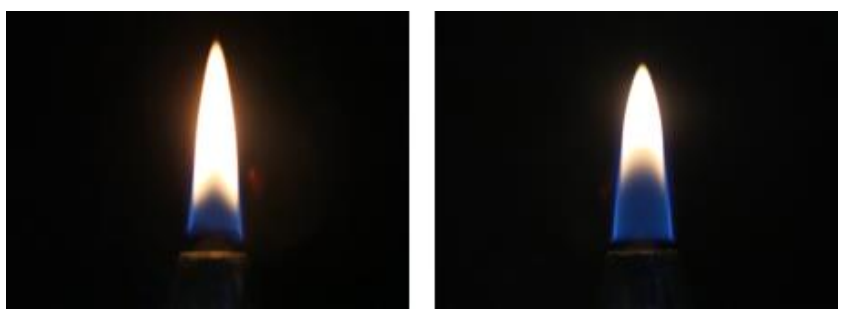

Fig. 5. Flame shape comparison (The left picture shows the RP-3 flame, and the right picture shows the biomass flame)

Fig. 6 shows the temperature profiles along the center axis of the two flames. The flame temperature in the experiment was measured by S-type $\mathrm{Pt}-\mathrm{Rh}$ thermocouple with error correction. It is obvious that the temperatures increase with the height above burner (HAB). Before the dimensionless height $\mathrm{H}=0.5$, the two curves of flame temperatures are close to each other. After $\mathrm{H}=0.5$, the biomass flame temperature is significantly higher than RP-3 flame.

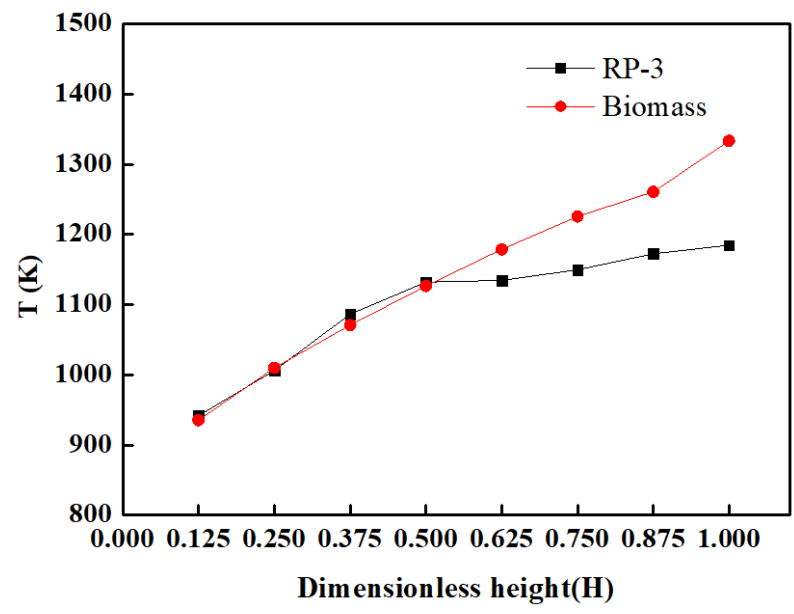

Fig.6. Temperature changes on the center axis of the flame

\section{RESULTS AND DISCUSSION}

\subsection{Soot morphology}

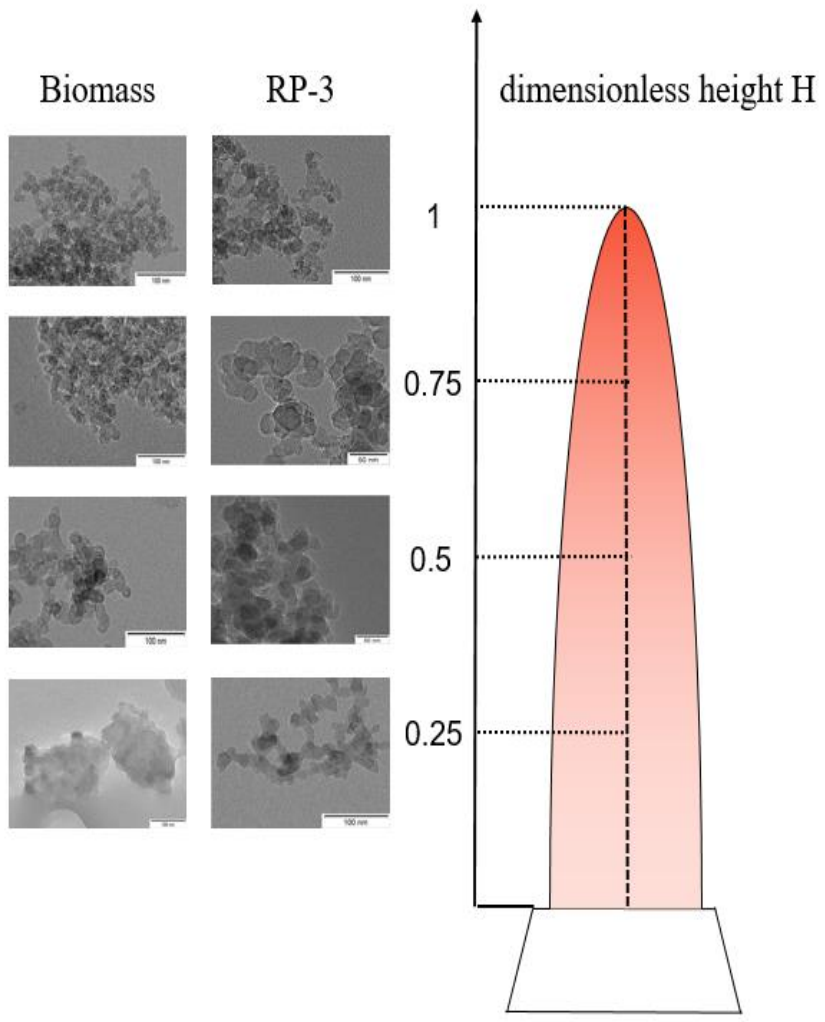

Fig. 7. TEM images of soot in RP-3 flame and biomass flame

Fig. 7 reports the TEM images of collected particles at different heights on the center axis of RP-3 flame and biomass flame. For RP-3 aviation kerosene flame, soot particles have just been born at a dimensionless height of 0.25 . The black nucleus can be observed inside some of the particles. Many particles have no obvious boundary contours, which are more look like fatty liquid. The primary particles can grow through the surface reaction, including the condensation of polycyclic aromatic hydrocarbon $\mathrm{PAH}$, dehydrogenation plus acetylene reaction (HACA mechanism) and condensation of smaller particles (Vander, wal.et al., 2004). At the dimensionless height of 0.5 , the infant soot is further developed into young soot, and the particle size of the soot is increased, mainly due to the effect of surface growth. At this time, soot particles with a clear boundary contour can be seen. At the dimensionless height of 0.75 , the sample has developed into mature soot particles, and the soot is more compactly aggregated, from the previous chain aggregation to the flake aggregation. The size of the soot particles is further increased also. Meanwhile, the single elementary particle is hardly observed. The particle size of the soot particles at the dimensionless height of 0.99 is reduced due to the oxidation of soot. For the results of biomass flames, it can be seen that the evolution of soot morphology is similar to that of RP-3 aviation kerosene flames. Both are in accordance with the soot formation theory established by Glassman (Glassman, I.1989). It shows that the generation of soot in liquid laminar diffusion flames has undergone several major stages. Pyrolysis of hydrocarbon fuels first produces precursor polycyclic aromatic hydrocarbons (PAH). When 
PAH grows to a certain extent, the particles nucleate to form a carbon atom with a diameter of 1-2 nm, and then undergo a stage of particle agglomeration, particle growth and particle oxidation, and agglomerate into the final combustion product - soot. The changes of soot particle sizes of the two flames are shown in Fig. 8. Among them, since the biomass soot is mainly fatty particles at $\mathrm{H}=0.25$, the soot particle size is not counted. These relevant parameters of soot morphology were resulted from applying the professional image processing software Image-Pro Plus to process TEM images. It can be seen that both soot increase first and then decrease with the increase of the dimensionless height. However, the size of biomass soot is significantly smaller than that of RP-3 soot at each stage.

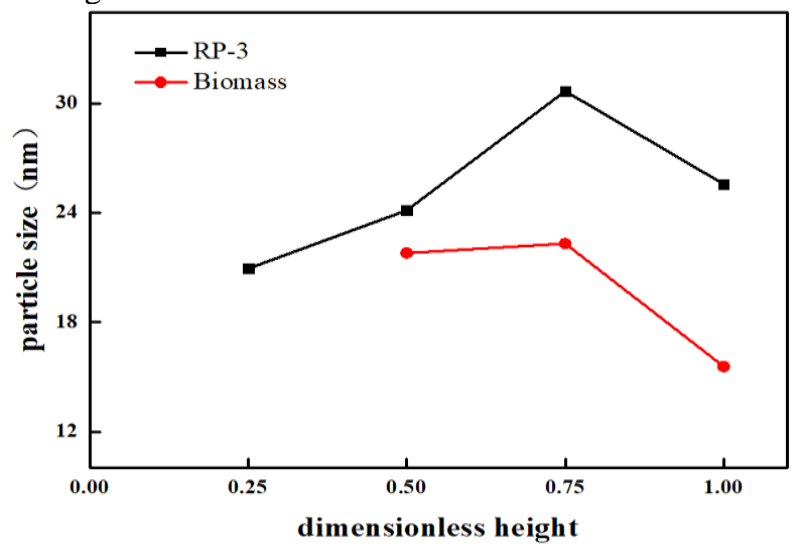

Fig. 8. Variation of soot particle size with dimensionless height

\subsection{Soot nanostructure}

The nanostructure of soot particles reflects not only the physical structure of soot at nanometer size (the overall distribution and arrangement of fringes), but also the degree of graphitization and oxidation-active chemical properties of soot. In this study, a professional image processing software Image $\mathbf{J}$ was used to analyze the microstructure of HRTEM photos. The nanostructure parameters such as layer spacing, microcrystal length and microcrystal curvature of soot particles were studied. Image processing includes the following processes: ( 1 ) ROI selection ( 2 ) image binarization (3) image dilate (4) image erode (5) image skeletonization (6) fringe correction. Fig. 9 shows the HRTEM images before and after image processing. Fig. 9a and $9 \mathrm{~b}$ are the representatives of RP-3 soot and biomass soot. Three nanostructure parameters can be directly extracted from the processed image.

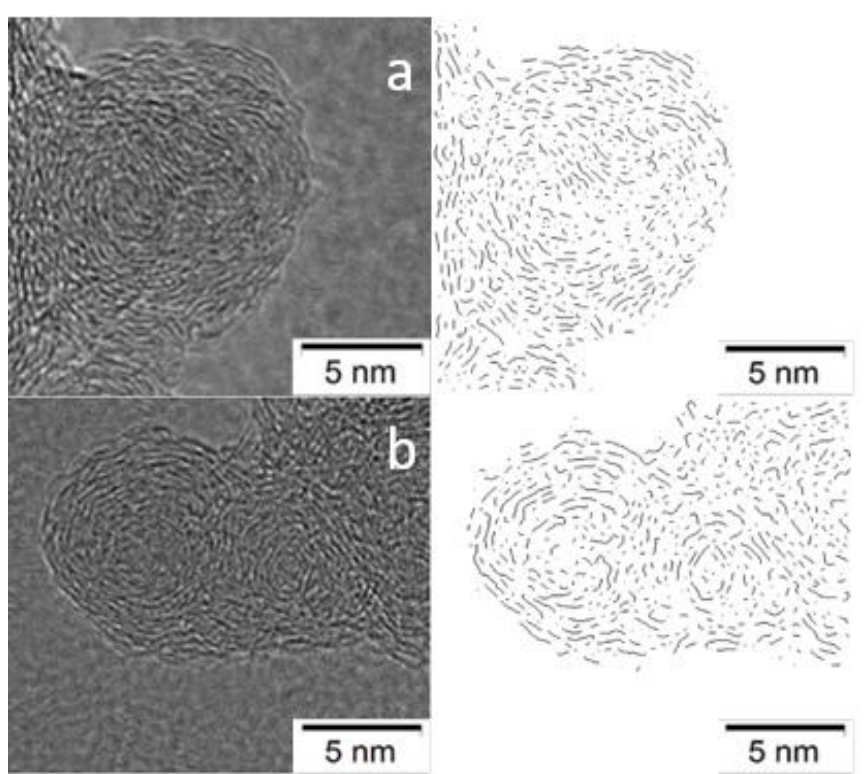

Fig. 9. HRTEM image processing result

HRTEM images of RP-3 soot samples are reported in Fig. 10. At the dimensionless height $\mathrm{H}=0.25$ of $\mathrm{RP}-3$ flame, the interior of soot particles is mainly amorphous carbon, and the carbon layer is in a disordered state without obvious graphitization structure. At dimensionless heights $\mathrm{H}=0.5$ and $\mathrm{H}=0.75$, soot particles show a certain degree of graphitization structure, which shows onion core-shell structure. The inner core of the particles is disordered amorphous carbon, and the outer core of the particles is an orderly carbon layer. The parallel and concentrically oriented aromatic layers or lamellae ordered in an onion-like structure constitute the graphitic-like part of soot, whereas the clusters of aromatic hydrocarbons without any apparent order represent the amorphous-like component of soot (Alfè, M.et al., 2009). In addition, some soot particles have a multi-core structure, and there are two possibilities for this phenomenon. Firstly, in the early stage of the development of soot, some particles collide and then grow on the surface, which in turn presents a multicore structure. Secondly, since the HRTEM image can only shows the soot in a two-dimensional plane state, there may be multiple soot stacks that cause the image to exhibit a multicore state. At the dimensionless height $\mathrm{H}=1$, the carbon atoms located at the edge of the carbon layer combine with other free radicals and active molecules due to the high temperature oxidation, so that the crystallite length and the degree of graphitization increases, and the reactivity decreases. 

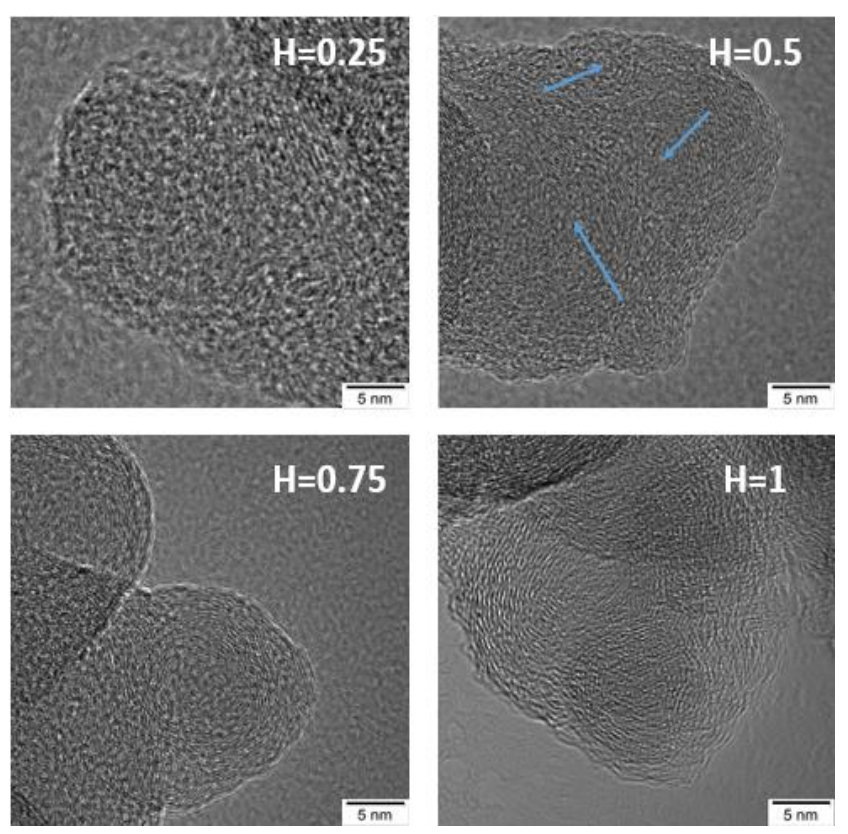

Fig. 10. HRTEM images of RP-3 soot samples

Fig. 11 shows the histogram of the frequency distribution of soot fringe length, layer spacing, and fringe tortuosity of RP-3 flame at different dimensionless heights. It shows that all three parameters show a distinct single peak distribution. In literature, relevant studies and carbon theory suggested a few regular patterns (Vander, wal.et al., 2004; Shim, HS.et al., 2000; Vander, wal.et al., 2005 ). The first is that the longer layer fringe length, the less active carbon atoms on its edge. The second means that the larger the spacing between layers, the more easily carbon atoms are oxidized. The last one concludes that the smaller fringe tortuosity, the less odd carbon rings in the carbon layer and easier to be reconstructed.
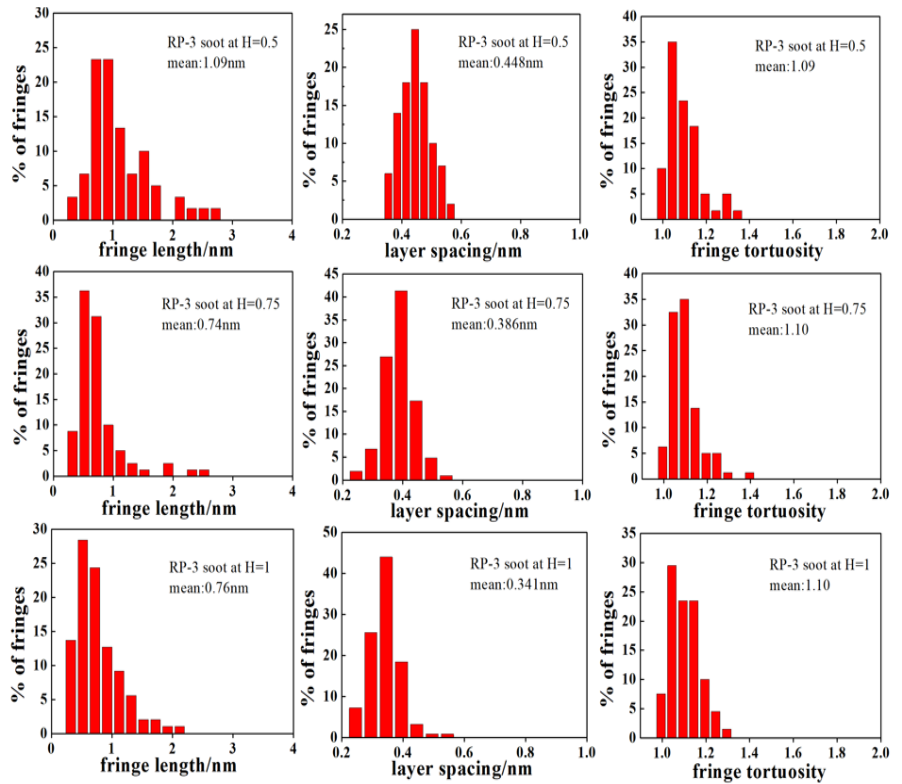

Fig. 11. Fringe length, layer spacing and fringe tortuosity distributions of RP-3 soot samples at $\mathrm{H}=0.5,0.75,1$
In this study, with the increase of dimensionless height, the fringe length decreased first and then increased. From $\mathrm{H}=0.5$ to $\mathrm{H}=0.75$, during the growth of soot particles, due to overlap between electron orbitals in the carbon layers, the repulsion between adjacent carbon layers is produced (Kholghy, M. et al., 2013). In order to achieve the minimum energy stable state, the fringe length of the carbon layers is reduced (Dresselhaus, MS.et al., 1996). As the particles approaching the flame tip from $\mathrm{H}=0.75$, the microcrystalline carbon layers on the surface of soot particles are oxidized due to the activity of their structure, which results in the increase of fringe length in the end. As the dimensionless height increases, the layer spacing decreases from $0.45 \mathrm{~nm}$ to 0.34 $\mathrm{nm}$, which is close to the carbon layer spacing of graphite of $0.335 \mathrm{~nm}$. This indicates that the degree of graphitization of RP-3 flame soot increases with the increase of dimensionless height, which is mutually verified with previous results. In addition, at different dimensionless heights, the change in fringe tortuosity is not obvious.
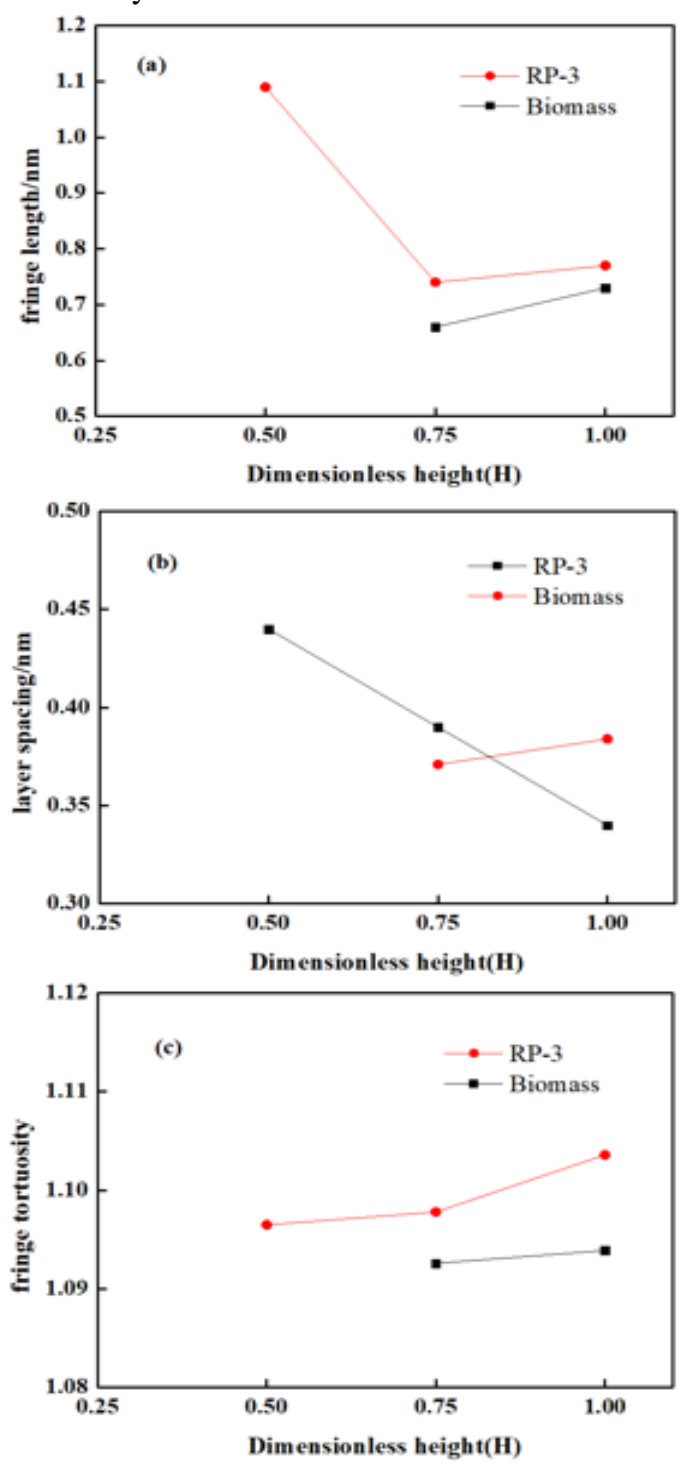

Fig. 12. Nanostructure parameters of soot generated at different sampling points in RP-3 and biomass 
The development of biomass flame soot nanostructure has a similar process to that of RP-3 flame. In the initial stage, the carbon is amorphous, and with the increase of dimensionless height, it presents the onion-like core-shell structure. Fig. 12 shows the comparison of the fringe length, layer spacing and fringe tortuosity of two kinds of flame soot. Among them, at the RP- 3 flame $\mathrm{H}=0.25$ and the biomass flame $\mathrm{H}=0.5$, the soot is mainly amorphous carbon, so the relevant parameters are not counted. It can be seen from Fig. 12(a) that at the dimensionless height $\mathrm{H}=0.75$ to $\mathrm{H}=1$, the fringe length of the two flame soot crystallites increases. Meanwhile, the fringe length in RP-3 flame was larger than that of biomass at $\mathrm{H}=1$, indicating a higher degree of graphitization. It can be seen from Fig. 12(b) that at the flame tip $\mathrm{H}=1$, the layer spacing of the RP-3 flame is smaller than that of the biomass. This also means that the RP-3 flame soot is more graphitized than biomass flame soot. It can be seen from Fig. 12(c) that the fringe tortuosity of both kinds of flame soot changed little and stabilized around 1.09 , but the tortuosity of RP-3 was slightly larger.

\subsection{X-ray diffraction}

In this study, X-ray diffraction and HRTEM were used to cross-characterize the structural differences between the soot particles by the two fuels. The XRD spectra of soot are shown in Fig. 16. The wide reflection at $23.1^{\circ}$ and $44.6^{\circ}$ indicates the formation of a crystalline phase that is attributed to the parallel graphite layer, representing the highly carbonized onion-like soot structure observed in the TEM morphology. The two reflections correspond to the 002 peak $\left(23.1^{\circ}\right)$ and the 101 peak $\left(44.6^{\circ}\right)$ of Griphite- $2 \mathrm{H}$, respectively. The reflection at $23.1^{\circ}$ spaced at a well-defined inter-planar distance represented the parallel graphite layers. The reflection at $44.6^{\circ}$ represented two-dimensional reflections, which arise from the ordering of carbon atoms inside the graphite layers, which take independently all reflections in space ( B.E. Warren,1941).

The 002 reflections of RP-3-soot were enhanced in comparison to that of biomass-soot, this phenomenon reveals the higher degree of graphene layer stacking ( Galvez A, et al. 2002). The relative lower intensity of the 101 peak of biomasssoot indicates the lower degree of graphitization (lateral extension of carbon nanostructures) compared to RP-3-soot because the intensity of the 101 peak indicates the proportion of ordered carbon structures.

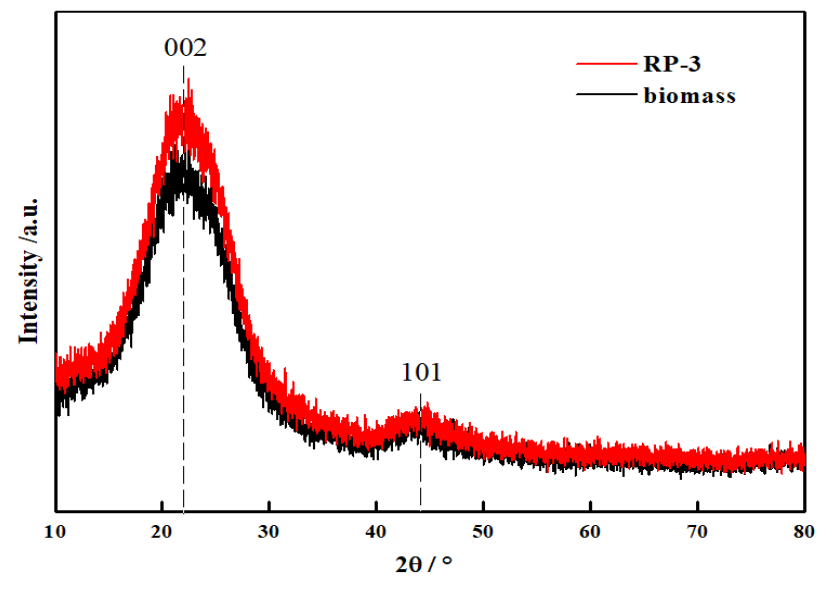

Fig. 13. XRD analysis of two flame soot samples

\subsection{Elemental analysis}

Table2 Elemental analysis of two flame soot samples

\begin{tabular}{cccccc}
\hline $\begin{array}{c}\text { Sample } \\
\text { Name }\end{array}$ & $(\mathrm{C}) \%$ & $(\mathrm{H}) \%$ & $(\mathrm{O}) \%$ & $(\mathrm{~N}) \%$ & $\mathrm{H} / \mathrm{C}$ \\
\hline RP-3 & 95.521 & 1.112 & 0.742 & 0.000 & 0.14 \\
Biomass & 90.779 & 1.655 & 3.085 & 0.000 & 0.22 \\
\hline
\end{tabular}

The types and contents of the elements contained in the two soot samples are shown in table 2. According to the results, both samples are mainly composed of $\mathrm{C}, \mathrm{H}$ and $\mathrm{O}$ elements, and the content of $\mathrm{C}$ is above $90 \%$. Compared with RP-3 soot, the content of $\mathrm{C}$ in biomass soot is relatively lower, but the content of $\mathrm{O}$ is higher. This result may be caused by the content of carboxylic acids, aldehydes, ketones, alcohols and other substances in biomass fuel. In general, the hydrogen content was directly associated to the availability of active sites of the solid, which meant it was involved in its reactivity toward $\mathrm{O}_{2}$ and $\mathrm{CO}_{2}$ (Abián, M.et al., 2012; Salamanca, Maurin.et al., 2012). The higher $\mathrm{H}$ content per unit $\mathrm{C}$ atom contributed to the increase in the possibility of $\mathrm{H}$ abstraction by oxygen to facilitate the oxidation, while the lower $\mathrm{H} / \mathrm{C}$ ratio was related to a lower probability of active sites available for oxidation attack. The reduction of $\mathrm{H} / \mathrm{C}$ (atom ratio) implied an increase of graphitic planar structures (Alfè, M.et al., 2009). The H/C of RP-3 soot is smaller than biomass soot, indicating that RP-3 soot has a higher degree of graphitization. This conclusion is verified with the previous results of HRTEM.

\section{CONCLUSIONS}

In this paper, the soot particles generated by the laminar diffusion flame formed by RP-3 aviation kerosene and a biomass aviation fuel respectively in a nitrogen transport environment were studied. A new direct sampling method was used to sample soot at different heights along the center axis of the flame. TEM, HRTEM, XRD and elemental analyzer were applied to study the evolution of soot morphology and nanostructure. The main conclusions of this study are summarized as follows:

(1)In the growth process of soot particles, due to the surface growth of soot and the oxidation of soot, the basic 
particle sizes of the two types of flame soot first increased and then decreased. At the tip of the flame, the basic particle size of RP-3 soot is $25.6 \mathrm{~nm}$, and the biomass soot is $15.6 \mathrm{~nm}$, which is only about $60 \%$ of the RP-3 soot in this study.

(2)The nanostructure of soot was analyzed based on HRTEM images. It can be seen that the two flames of soot are gradually transformed from the initial amorphous carbon structure into a typical onion-like core-shell structure. The core is amorphous carbon and the outer shell consists of crystallites with the same orientation or parallel. With the increase of the dimensionless height, the layer spacing of RP3 soot gradually decreases, which indicates that the degree of graphitization of the soot is enhanced. Compared with the biomass soot, the RP-3 soot at the tip of the flame has longer fringe length and smaller layer spacing, which indicates a higher degree of graphitization.

(3)The results of elemental analysis show that aviation kerosene soot has a lower $\mathrm{H} / \mathrm{C}$ ratio than biomass soot, which means that it is more graphitized. This is verified by the results of HRTEM.

In this study, the evolution of soot morphology and nanostructure in the free jet laminar diffusion flame is studied, which provides a scientific reference for studies on environmental pollution and low pollution emissions of aeroengines.

\section{ACKNOWLEDGMENTS}

This work was financially supported by the National Natural Science Foundation of China (NO. 91741128).

\section{REFERENCES}

Abián, M, Jensen, AD, Glarborg, P, Alzueta, MU. (2012). Soot reactivity in conventional combustion and oxy-fuel combustion environments. Energy \& Fuels, 26(8), 53375344.Doi: 10.1021/ef400620g

B. Apicella, A. Ciajolo, A, Tregrossi (2018). HRTEM and EELS investigations of flame-formed soot nanostructure. Fuel, 225: 218-224. Doi:10.1016/j.fuel.2018.03.091

B. Apicella, P. Pré, M. Alfè, A. Ciajolo, V. Gargiulo, C. Russo, A. Tregrossi, D. Deldique, J.N. Rouzaud (2015). Soot nanostructure evolution in premixed flames by high resolution electron transmission microscopy (HRTEM). Proceedings of the Combustion Institute.35 (2015) 1895-1902.Doi: 10.1016/j.proci.2014.06.121

B.E. Warren. X-ray study of the graphitization of carbon black. Phys Rev, 59 (1941), pp. 693-698.

Chen X, F. Tian, C. Persson, W. Duan, N.X. Chen,(2013) Interlayer interactions in graphite. Sci. Rep. UK 3 (2013) 3046.

Dresselhaus MS, Dresselhaus G, Eklund, PC (1996). Science of Fullerenes and Carbon Nanotubes: Their Properties and Applications. San Diego: Academic Press.

Galvez A, Boime NH, Cécile Reynaud, Christian Clinard, Jean-Noël Rouzaud. ( 2002 ) Carbon nanoparticles from laser pyrolysis. Carbon, 40: 2775-2789. Doi:10.1016/S00086223(02)00195-1

Ghiassi H, Toth P, Jaramillo I, Lighty, J. (2016). Soot oxidation-induced fragmentation: part 1: the relationship between soot nanostructure and oxidation-induced fragmentation. Combustion and Flame, 163, 179-187. Doi:10.1016/j.combustflame.2015.09.023

Glassman, I. (1989). Soot formation in combustion processes. Symposium on Combustion, 22(1), 295-311.Doi: 10.1016/s0082-0784(89)80036-0

J.P. Mathews, V. Fernandez-Also, A.D. Jones, H.H. Schobert (2010). Determining the molecular weight distribution of Pocahontas No. 3 low-volatile bituminous coal utilizing HRTEM and laser desorption ionization mass spectra data. Fuel 89, 1461-1469.Doi: 10.1016/j.fuel.2009.10.014

Kholghy M, Saffaripour M, Yip C, Thomson MJ. (2013). The evolution of soot morphology in a laminar coflow diffusion flame of a surrogate for jet a-1. Combustion and Flame.160(10),21192130.Doi:10.1016/j.combustflame.2013. 04.008

Liu F, Guo H, Smallwood GJ, Gülder öL. (2003). Numerical modelling of soot formation and oxidation in laminar coflow non-smoking and smoking ethylene diffusion flames. Combustion Theory and Modelling, 7(2), 301-315. Doi:10.1088/1364-7830/7/2/305

Li Z, Qiu L, Cheng X. (2018). The evolution of soot morphology and nanostructure in laminar diffusion flame of surrogate fuels for diesel. Fuel, 211 : 517-528. Doi:10.1016/j.fuel.2017.09.036

M. Alfè, Apicella B, Barbella R, Rouzaud JN, Tregrossi A, Ciajolo A. (2009). Structure-property relationship in nanostructures of young and mature soot in premixed flames. Proceedings of the Combustion Institute, 32(1), 697-704. Doi:10.1016/j.proci.2008.06.193

M.L. Botero, D. Chen, S. González-Calera, D. Jefferson, M. Kraft. (2016). HRTEM evaluation of soot particles produced by the non-premixed combustion of liquid fuels. Carbon, 96, 459-473. Doi:10.1016/j.carbon.2015.09.077

Matti M, Stephen J. Harris, Joseph J. (2003). Soot size distributions in rich premixed ethylene flames. Combustion \& Flame, 132(3), 328-342.Doi: 10.1016/s0010-2180(02)005023

Smooke MD, Mcenally C, Pfefferle L. (1999). Computational and experimental study of soot formation in a co-flow laminar ethylene diffusion flame. Combustion \& Flame, 117(1-2),117-139.Doi:10.1016/s00102180(98)000960

Salamanca Maurin, Velásquez M, Mondragón F, Santamaría A.(2012) Variations of the soot precursors chemical composition induced by ethanol addition to fuel. Energy Fuels, 26:6602-11.Doi: 10.1021/ef300926y

Santoro RJ, Yeh TT, Horvath JJ, Semerjian HG. (1987)The transport and growth of soot particles in laminar diffusion flames. Combustion Science and Technology. 53: 89-115.Doi: 10.1080/00102208708947022

Shim HS, Hurt RH, Yang, N. Y. C. (2000). A methodology for analysis of 002 lattice fringe images and its application to combustion-derived carbons. Carbon, 38(1), 2945.Doi:10.1016/s0008-6223 (99)00096-2

Vander Wal RL, Tomasek AJ. (2003). Soot oxidation: dependence upon initial nanostructure. Combustion \& Flame, 134 (2003) 1-9. 
Vander Wal RL, Tomasek AJ. (2004). Soot nanostructure: dependence upon synthesis conditions. Combustion \& Flame, 136(1-2), 129-140. Doi:10.1016/j.combustflame.2003.09.008

Vander Wal RL, Tomasek A J, King J D (2005). A method for structural characterization of the range of cylindrical nanocarbons: nanotubes to nanofibers. Carbon, 43(14), 2918-2930. Doi:10.1016/j.carbon.2005.06.026

Wang X, Jin Q, Zhang J. (2018). Soot formation during polyurethane $(\mathrm{pu})$ plastic pyrolysis: the effects of temperature and volatile residence time. Energy Conversion and Management, 164, 353-362. Doi:10.1016/j.enconman.2018.02.082

Zhao B. (2017). Study on preparation of biological aviation coal by hydrogenation of nannochloropsis. $\mathrm{PhD}$ thesis, Beihang University. 